\title{
COMMUNICATION
}

\section{A new method to prevent degradation of lithium- oxygen batteries: reduction of superoxide by viologen}

\author{
L. Yang ${ }^{a}$, J. T. Frith ${ }^{a}$, N. Garcia-Araez ${ }^{a, *}$ and J. R. Owen ${ }^{a}, *$
}

Received ooth January 2012,

Accepted ooth January 2012

DOI: $10.1039 / \times 0 x x 00000 x$

www.rsc.org/

Lithium-oxygen battery development is hampered by degradation reactions initiated by superoxide, which is formed in the pathway of oxygen reduction to peroxide. This work demonstrates that the superoxide lifetime is drastically decreased upon addition of ethyl viologen, which catalyses the reduction of superoxide to peroxide.

Lithium-oxygen batteries can potentially deliver 5 times more energy than lithium-ion batteries of the same weight. ${ }^{1-7}$ The energy is provided by the electrochemical reaction between $\mathrm{Li}$ and $\mathrm{O}_{2}$, typically forming $\mathrm{Li}_{2} \mathrm{O}_{2}$. Since all these compounds are very light, the mass of the battery can be very small, leading to a high specific energy (i.e. energy per mass). However, several factors hamper the practical performance of current lithium-oxygen batteries. First of all, superoxide is formed as the first product of the reduction of $\mathrm{O}_{2}: 8$, 9

$\mathrm{O}_{2}+\mathrm{e}^{-}+\mathrm{Li}^{+} \rightarrow \mathrm{LiO}_{2}$

It has been shown that superoxide reacts irreversibly with most known electrolytes ${ }^{10}$ and it is also probably involved in the corrosion of carbon electrodes. ${ }^{11}$ Intensive research has been done on finding alternative electrolytes and electrode materials that are resistant towards degradation by superoxide. A few solvents like dimethyl sulfoxide $^{12}$, some glymes ${ }^{13,14}$ and pyrrolidinium or piperidinium based ionic liquids ${ }^{15-19}$ have been identified as promising electrolyte choices. Gold ${ }^{12}$ and $\mathrm{TiC}^{20}$ electrodes have shown much better capacity performance than carbon, in terms of cycling stability and suppression of side reactions.

An alternative approach to solve the superoxide problem is the introduction of catalysts to promote the reduction of superoxide to peroxide:

$\mathrm{LiO}_{2}+\mathrm{e}^{-}+\mathrm{Li}^{+} \rightarrow \mathrm{Li}_{2} \mathrm{O}_{2}$

This would decrease the lifetime of superoxide and, with this, the long-term durability of the battery. If the superoxide lifetime were short enough, it would be conceivable that a wider range of materials could be incorporated in lithium-oxygen batteries without serious problems of degradation reactions. In addition, such catalysts would also be beneficial in order to speed up the overall 2-electron reduction of oxygen to $\mathrm{Li}_{2} \mathrm{O}_{2}$. In the absence of such catalyst, $\mathrm{Li}_{2} \mathrm{O}_{2}$ is usually formed by disproportionation of $\mathrm{LiO}_{2}: 8,9$

$2 \mathrm{LiO}_{2} \rightarrow \mathrm{O}_{2}+\mathrm{Li}_{2} \mathrm{O}_{2}$

However, as will be shown below, the rate of this reaction is very slow at low superoxide concentrations.

Another important issue in lithium-oxygen batteries is that the discharge product, $\mathrm{Li}_{2} \mathrm{O}_{2}$, deposits on the surface of the electrode, blocking its electrochemical activity. This produces a very early end of discharge, with little discharge product being formed, and little capacity being delivered. An innovative solution to solve this problem is the introduction of soluble redox shuttles that can displace the formation of $\mathrm{Li}_{2} \mathrm{O}_{2}$ from the electrode surface to the solution, by reducing oxygen through a homogenous chemical reaction. ${ }^{21,} 22$ Soluble redox couples have also been used as mediators for the evolution of oxygen in lithium-oxygen batteries, resulting in major performance improvements. ${ }^{23-26}$

In the present work, we have studied the application of soluble redox couples with the dual purpose of preventing electrode passivation and enhancing the 2-electron oxygen reduction. We demonstrate that ethyl viologen acts as a homogenous electrocatalyst that enhances the 2-electron reaction of oxygen to $\mathrm{Li}_{2} \mathrm{O}_{2}$ while mitigating electrode passivation. It has been previously shown that superoxide and viologen react irreversibly forming a range of degradation products. ${ }^{27}$ However, we demonstrate that under our experimental conditions the extent of degradation of viologen by superoxide attack is negligible, a fact that we attribute to the presence of an excess of lithium cations in solution. 
Figure 1 shows the galvanostatic discharge and charge of a glassy carbon electrode in an oxygen-saturated solution with (a) and without (b) ethyl viologen, $\mathrm{EtV}^{2+}$ (see supplementary information for full experimental details). It is observed that, in the absence of $\mathrm{EtV}^{2+}$, the discharge curve plateaus at ca. $2.39 \mathrm{~V}$ vs. $\mathrm{Li} / \mathrm{Li}^{+}$, whereas with $\mathrm{EtV}^{2+}$. a higher discharge voltage is observed, ca $2.42 \mathrm{~V}$ vs. $\mathrm{Li} / \mathrm{Li}^{+}$. This is associated to the mediation action of $\mathrm{EtV}^{2+}$, which results in a lower overpotential for the reduction of oxygen. Consequently, the reduction of oxygen is triggered by the reduction of $\mathrm{EtV}^{2+}$ to $\mathrm{EtV}^{+}$, that plateaus at the standard potential $\mathrm{E}^{0}\left(\mathrm{EtV}^{2+} /\right.$ $\mathrm{EtV}^{+}$) $\approx 2.42 \mathrm{~V}$ vs. $\mathrm{Li} / \mathrm{Li}^{+}$(supporting information, figure S2). This reaction is followed by the reduction of $\mathrm{O}_{2}$ by $\mathrm{EtV}^{+}$:

$2 \mathrm{EtV}^{+}+\mathrm{O}_{2}+2 \mathrm{Li}^{+} \rightarrow 2 \mathrm{EtV}^{2+}+\mathrm{Li}_{2} \mathrm{O}_{2}$

Since the thermodynamic potential for the reduction of oxygen to $\mathrm{Li}_{2} \mathrm{O}_{2}$ is ca. $3 \mathrm{~V}$ vs. $\mathrm{Li} / \mathrm{Li}^{+},{ }^{28,} 29$ the reaction above is thermodynamically favourable.

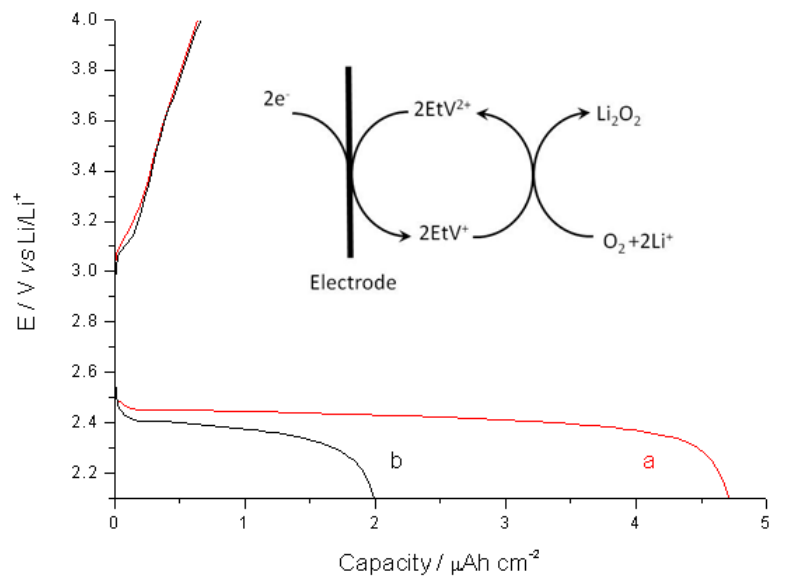

Figure 1. Galvanostatic discharge and charge of a glassy carbon electrode in oxygen-saturated Py ${ }_{14}$ TFSI containing $0.1 \mathrm{M}$ LiTFSI, with (a) and without (b) $2 \mathrm{mM} \mathrm{EtV}{ }^{2+}$. I $=20 \mu \mathrm{A} \mathrm{cm}^{-2}$. The inset sketches the redox shuttle action of viologen, displacing the formation of $\mathrm{Li}_{2} \mathrm{O}_{2}$ from the electrode surface to the solution.

Another remarkable feature in figure 1 is the increase in the discharge capacity upon addition of viologen. This is due to the shuttle action of viologen (see inset figure 1). In the presence of viologen, $\mathrm{Li}_{2} \mathrm{O}_{2}$ is formed in solution, at a certain distance from the electrode surface. Therefore, the passivation of the electrode by $\mathrm{Li}_{2} \mathrm{O}_{2}$ deposition is less severe, affording a higher discharge capacity.

While the results in figure 1 demonstrate that viologen is a mediator of the oxygen reduction reaction, the reaction path is not unique. It is possible to propose that viologen acts as a mediator of the reduction of oxygen to superoxide, which will then disproportionate forming oxygen and peroxide:

$$
\begin{aligned}
& \mathrm{EtV}^{2+}+\mathrm{e}^{-} \rightarrow \mathrm{EtV}^{+} \\
& \mathrm{EtV}^{+}+\mathrm{O}_{2}+\mathrm{Li}^{+} \rightarrow \mathrm{EtV}^{2+}+\mathrm{LiO}_{2} \\
& 2 \mathrm{LiO}_{2} \rightarrow \mathrm{O}_{2}+\mathrm{Li}_{2} \mathrm{O}_{2}
\end{aligned}
$$

Alternatively, viologen may mediate the 2-electron reduction of oxygen. In other words, viologen will not only reduce oxygen to superoxide, but it will also reduce superoxide to peroxide:

$\mathrm{EtV}^{2+}+\mathrm{e}^{-} \rightarrow \mathrm{EtV}^{+}$
$\mathrm{EtV}^{+}+\mathrm{O}_{2}+\mathrm{Li}^{+} \rightarrow \mathrm{EtV}^{2+}+\mathrm{LiO}_{2}$

$\mathrm{EtV}^{+}+\mathrm{LiO}_{2}+\mathrm{Li}^{+} \rightarrow \mathrm{EtV}^{2+}+\mathrm{Li}_{2} \mathrm{O}_{2}$

The second reaction path is more advantageous because the overall rate of the reaction would be faster (we will show below that the disproportionation step, reaction 7 , is extremely slow at low superoxide concentrations). Furthermore, the lifetime of superoxide would be decreased, and consequently, the chemical stability of the battery would be improved for the reasons stated above.

In order to distinguish between these two reaction paths, we first studied the kinetics of $\mathrm{LiO}_{2}$ disproportionation. For that purpose, we dissolved $\mathrm{KO}_{2}$ in a solution containing an excess of $\mathrm{Li}^{+}$, and we followed the decrease in superoxide concentration by UV-vis measurements. This method was previously used in order to study the lifetime of superoxide anions in the absence of $\mathrm{Li}^{+}$, concluding that superoxide anions are long lived in some electrolytes such as dimethylsulfoxide, ${ }^{30}$ glymes $^{13}$ and pyrrolidinium based ionic liquids. ${ }^{19}$ In this work we have observed that superoxide anions are also stable in solutions with high concentration of $\mathrm{Li}^{+}$, for superoxide concentrations $<1 \mathrm{mM}$. Figure 2 shows that the absorption band of superoxide in a $0.1 \mathrm{mM} \mathrm{KO}_{2}$ solution with 300 $\mathrm{mM}$ of LiTFSI decreases by less than $1 \%$ after 3 hours. Similar stability is observed at a $\mathrm{KO}_{2}$ concentration of $1 \mathrm{mM}$ (supporting information, figure S3). These measurements were done in acetonitrile, which is a solvent with low donor number. It has been suggested that the lifetime of lithium superoxide is longer in solvents with high donor number, ${ }^{31,} 32$ and we have observed that in tetraglyme the lithium superoxide lifetime is $>3$ hours (supplementary information, figure S4). Previous work showed that superoxide disproportionates to $\mathrm{O}_{2}$ and $\mathrm{Li}_{2} \mathrm{O}_{2}$ in the presence $\mathrm{Li}^{+},{ }^{33}$ but we have found that the disproportionation reaction is only fast for high superoxide concentrations, and particularly, in the presence of an excess of solid $\mathrm{KO}_{2}$.

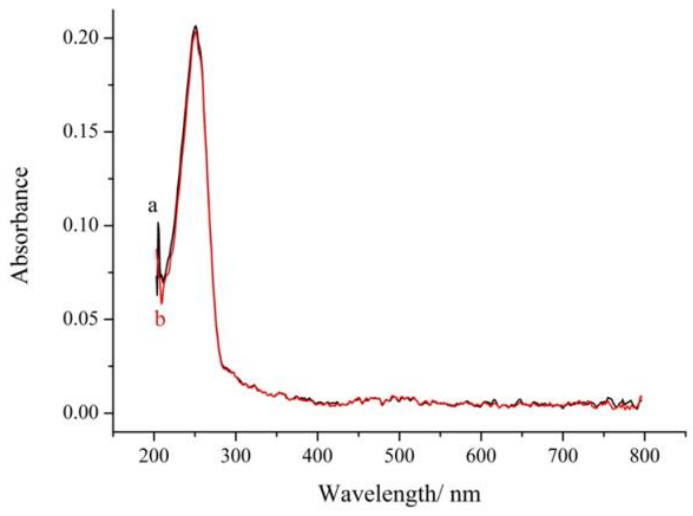

Figure 2. UV-vis spectra of a ca. $0.1 \mathrm{mM} \mathrm{KO}_{2}$ solution in acetonitrile before (a) and 3 hours after the addition of $300 \mathrm{mM}$ LiTFSI (b).

Next, we studied the reaction between $\mathrm{LiO}_{2}$ and $\mathrm{EtV}^{+}$, and we observed that superoxide reacted rapidly in the presence of $\mathrm{EtV}^{+}$. Figure 3 shows the UV-vis spectra obtained during the titration of a $\mathrm{EtV}^{+}$solution with superoxide. As shown in figure 3, the absorption bands characteristic of $\mathrm{EtV}^{+}$at 600 and $400 \mathrm{~nm}$ decrease with the addition of superoxide aliquots, while the band at $260 \mathrm{~nm}$ characteristic of $\mathrm{EtV}^{2+}$ grows (see supporting information, figure S1 
for the band assignment). Taking into account the decrease in the absorption at $600 \mathrm{~nm}$, it is demonstrated that one mole of $\mathrm{LiO}_{2}$ reacts with ca. one mole of $\mathrm{EtV}^{+}$(the details of the calculation are in the supporting information). The stoichiometry of the reaction thus demonstrates that a direct reduction of superoxide by viologen occurs as the second step of the 2- electron mediation suggested above (reaction 9).

In order to demonstrate the absence of a degradation reaction of viologen by the attack of superoxide, the oxidized viologen was rereduced at the end of the experiment using $\mathrm{Li}_{7} \mathrm{Ti}_{5} \mathrm{O}_{12}$ :

$3 \mathrm{EtV}^{2+}+\mathrm{Li}_{7} \mathrm{Ti}_{5} \mathrm{O}_{12} \rightarrow 3 \mathrm{EtV}^{+}+\mathrm{Li}_{4} \mathrm{Ti}_{5} \mathrm{O}_{12}+3 \mathrm{Li}^{+}$

Figure 3 compares the spectrum of the $\mathrm{EtV}^{+}$before (curve a) and after (curve e) the reaction with superoxide followed by re-reduction with $\mathrm{Li}_{7} \mathrm{Ti}_{5} \mathrm{O}_{12}$. An excellent agreement is observed, demonstrating that the extent of viologen degradation is negligible. In conclusion, the results in figure 3 are consistent with the viologen mediated reduction of superoxide to peroxide.

It is noteworthy that the mediation action of viologen for the 2electron reduction of oxygen appears to hold in various solvents, including acetonitrile and Py ${ }_{14}$ TFSI (supporting information, figures $\mathrm{S} 5-7$ ), and that the titration of a solution of $\mathrm{EtV}^{+}$with $\mathrm{O}_{2}$ confirms that ca 2 moles of $\mathrm{EtV}^{+}$react with one mol of $\mathrm{O}_{2}$.

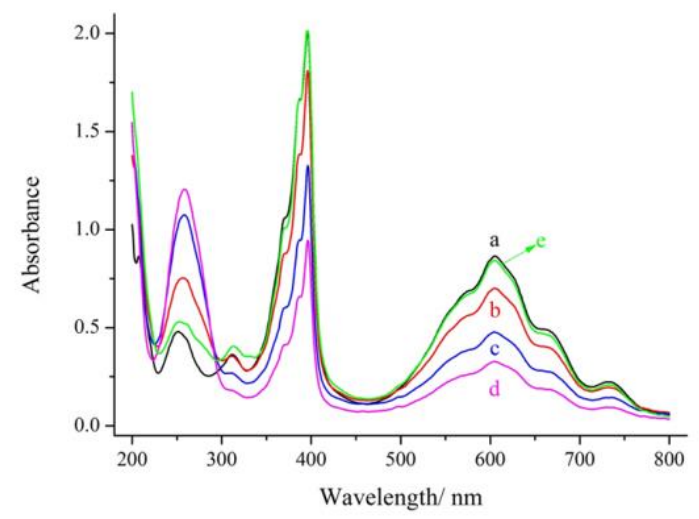

Figure 3. UV-vis spectra measured during the titration of $0.05 \mathrm{mM}$ $\mathrm{EtV}^{+}+0.15 \mathrm{M}$ LiTFSI in acetonitrile with: a) zero, b) one, c) two, and d) three additions of $0.0125 \mathrm{mM} \mathrm{KO}$. Curve (e) shows the spectrum obtained after re-reduction with $\mathrm{Li}_{7} \mathrm{Ti}_{5} \mathrm{O}_{12}$.

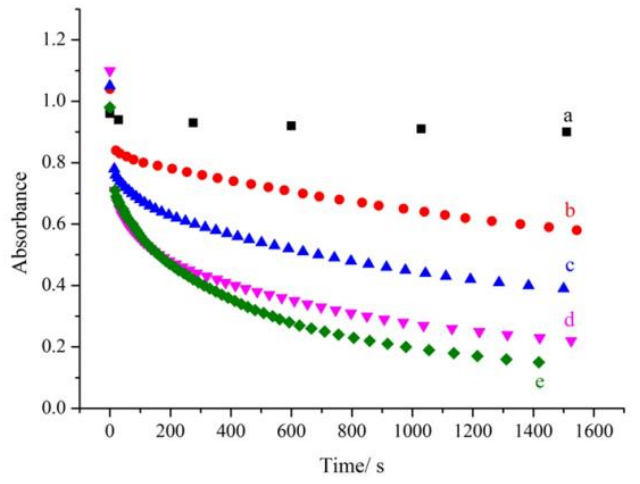

Figure 4. Absorbance at $590 \mathrm{~nm}$ of a solution that was initially 0.1 $\mathrm{mM} \mathrm{EtV}++0.1 \mathrm{mM} \mathrm{KO}_{2}$ in acetonitrile, measured as a function of time. The LiTFSI concentration is: a) 1, b) 75 , c) 150 , d) 300 , and e) $600 \mathrm{mM}$.
Finally, the reaction rate between $\mathrm{EtV}^{+}$and superoxide was monitored by measuring the absorbance at $590 \mathrm{~nm}$, which is proportional to the $\mathrm{EtV}^{+}$concentration, as a function of time (figure 4), at different $\mathrm{Li}^{+}$concentrations. These measurements provide a direct probe of the superoxide lifetime, and in addition, the analysis of the reaction kinetics confirms the direct reaction between $\mathrm{EtV}^{+}$ and superoxide, since it is concluded that the reaction of $\mathrm{EtV}^{+}$and superoxide follows third order kinetics (see supporting information): $\mathrm{d}\left[\mathrm{EtV}^{+}\right] / \mathrm{dt}=\mathrm{k}\left[\mathrm{Li}^{+}\right]\left[\mathrm{O}_{2}^{-}\right]\left[\mathrm{EtV}^{+}\right]$

where the rate constant, $\mathrm{k}$, equals to ca. $90 \mathrm{M}^{-2} \mathrm{~s}^{-1}$. The reaction between $\mathrm{EtV}^{+}$and $\mathrm{O}_{2}$ is even faster, consistent with the reaction mechanism with reactions 8,9 and 10 (see supporting information).

To finish, it should be emphasized that the presence of viologen produces an enormous decrease in the lifetime of superoxide. While in the absence of viologen, the lifetime of superoxide is $>3$ hours for superoxide concentrations $<1 \mathrm{mM}$, in the presence of only $0.1 \mathrm{mM}$ $\mathrm{EtV}^{+}$, the concentration of superoxide is decreased by half in only 3 minutes (figure 4).

\section{Conclusions}

We have shown that ethyl viologen acts as a homogeneous catalyst for the 2-electron reduction of oxygen in lithium-oxygen batteries. An enormous decrease in the lifetime of superoxide is observed upon addition of ethyl viologen to the solution, even at the sub-millimolar concentration. These findings open up a new strategy to improve the performance and durability of lithium-oxygen batteries.

The aim of this work was not to propose ethyl viologen as the perfect solution to lithium-oxygen batteries, since we are aware of some shortcomings (toxicity, slightly low redox potential, slow diffusion, etc.). The aim was to demonstrate, for the first time, the concept of employing a soluble redox couple in order to decrease the lifetime of superoxide in a lithium-oxygen battery by promoting the 2-electron reduction of oxygen.

\section{Acknowledgements}

The authors acknowledge the funding provided by the EU FP7 "LABOHR" NMP3-SL-2011-265971 project. Prof. Phil Bartlett and the partners of LABOHR are acknowledged for fruitful discussions.

\section{Notes and references}

${ }^{a}$ University of Southampton, Chemistry, SO17 1BJ, United Kingdom Experimental details and additional experimental data are available in the Electronic Supplementary Information: See DOI: 10.1039/b000000x/

1. P. G. Bruce, S. A. Freunberger, L. J. Hardwick and J. M. Tarascon, Nat Mater., 2012, 11, 19-29.

2. J. Christensen, P. Albertus, R. S. Sanchez-Carrera, T. Lohmann, B. Kozinsky, R. Liedtke, J. Ahmed and A. Kojic, J. Electrochem. Soc., 2012, 159, R1-R30.

3. R. Black, B. Adams and L. F. Nazar, Adv. Energy Mater., 2012, 2, 801-815.

4. Y. Y. Shao, S. Park, J. Xiao, J. G. Zhang, Y. Wang and J. Liu, ACS Catal., 2012, 2, 844-857.

5. N. Garcia-Araez and P. Novak, J. Solid State Electrochem., 2013, 17, 1793-1807.

6. G. Girishkumar, B. McCloskey, A. C. Luntz, S. Swanson and W. Wilcke, J. Phys. Chem. Lett., 2010, 1, 2193-2203. 
7. Y. C. Lu, B. M. Gallant, D. G. Kwabi, J. R. Harding, R. R. Mitchell, M. S. Whittingham and Y. Shao-Horn, Energy Environ. Sci., 2013, 6, 750-768.

8. C. O. Laoire, S. Mukerjee, K. M. Abraham, E. J. Plichta and M. A. Hendrickson, J. Phys. Chem. C, 2009, 113, 20127-20134.

$9 . \quad$ Z. Q. Peng, S. A. Freunberger, L. J. Hardwick, Y. H. Chen, V. Giordani, F. Barde, P. Novak, D. Graham, J. M. Tarascon and P. G. Bruce, Angew. Chem. Int. Ed., 2011, 50, 6351-6355.

10. S. A. Freunberger, Y. H. Chen, Z. Q. Peng, J. M. Griffin, L. J. Hardwick, F. Barde, P. Novak and P. G. Bruce, J. Am. Chem. Soc., 2011, 133, 8040-8047.

11. D. M. Itkis, D. A. Semenenko, E. Y. Kataev, A. I. Belova, V. S. Neudachina, A. P. Sirotina, M. Havecker, D. Teschner, A. KnopGericke, P. Dudin, A. Barinov, E. A. Goodilin, Y. Shao-Horn and L. V. Yashina, Nano Lett., 2013, 13, 4697-4701.

$12 . \quad$ Z. Q. Peng, S. A. Freunberger, Y. H. Chen and P. G. Bruce, Science, 2012, 337, 563-566.

13. K. U. Schwenke, S. Meini, X. H. Wu, H. A. Gasteiger and M Piana, PCCP, 2013, 15, 11830-11839.

14. S. A. Freunberger, Y. H. Chen, N. E. Drewett, L. J. Hardwick, F. Barde and P. G. Bruce, Angewandte Chemie-International Edition, 2011, 50, 8609-8613.

15. F. Soavi, S. Monaco and M. Mastragostino, J. Power Sources, 2013, 224, 115-119.

16. J. T. Frith, A. E. Russell, N. Garcia-Araez and J. R. Owen, Electrochem. Commun., 2014, 46, 33-35.

17. J. Herranz, A. Garsuch and H. A. Gasteiger, Journal of Physical Chemistry C, 2012, 116, 19084-19094.

18. K. Takechi, S. Higashi, F. Mizuno, H. Nishikoori, H. Iba and T. Shiga, ECS Electrochem. Lett., 2012, 1, A27-A29.

$19 . \quad$ M. Hayyan, F. S. Mjalli, M. A. Hashim, I. M. AlNashef, S. M. AlZahrani and K. L. Chooi, J. Electroanal. Chem., 2012, 664, 26-32.

20. M. M. O. Thotiyl, S. A. Freunberger, Z. Q. Peng, Y. H. Chen, Z. Liu and P. G. Bruce, Nat Mater., 2013, 12, 1049-1055.

21. M. J. Lacey, J. T. Frith and J. R. Owen, Electrochem. Commun., 2013, 26, 74-76.

22. D. Sun, Y. Shen, W. Zhang, L. Yu, Z. Yi, W. Yin, D. Wang, Y. Huang, J. Wang, D. Wang and J. B. Goodenough, J. Am. Chem. Soc., 2014, 136, 8941-8946.

23. G. V. Z. Chase, S.; Walker, W.; Uddin, J.; Sasaki, K. A.; Giordani, V.; Bryantsev, V.; Blanco, M.; Addison, D. D., Patent WO2011133982A1, 2011.

24. Y. H. Chen, S. A. Freunberger, Z. Q. Peng, O. Fontaine and P. G. Bruce, Nat. Chem., 2013, 5, 489-494.

25. H.-D. Lim, H. Song, J. Kim, H. Gwon, Y. Bae, K.-Y. Park, J. Hong, H. Kim, T. Kim, Y. H. Kim, X. Lepró, R. Ovalle-Robles, R. H. Baughman and K. Kang, Angew. Chem. Int. Ed., 2014, 53, 3926-3931.

26. T. H. Yoon and Y. J. Park, RSC Adv., 2014, 4, 17434-17442.

27. E. J. Nanni, C. T. Angelis, J. Dickson and D. T. Sawyer, J. Am. Chem. Soc., 1981, 103, 4268-4270.

28. K. M. Abraham and Z. Jiang, J. Electrochem. Soc., 1996, 143, 15.

29. Y.-C. Lu, H. A. Gasteiger, M. C. Parent, V. Chiloyan and Y. Shao-Horn, Electrochem. Solid-State Lett., 2010, 13, A69-A72

30. S. Kim, R. Dicosimo and J. S. Filippo, Anal. Chem., 1979, 51, 679-681.

31. C. O. Laoire, S. Mukerjee, K. M. Abraham, E. J. Plichta and M. A. Hendrickson, J. Phys. Chem. C, 2010, 114, 9178-9186.

32. M. J. Trahan, I. Gunasekara, S. Mukerjee, E. J. Plichta, M. A. Hendrickson and K. M. Abraham, J. Electrochem. Soc., 2014, 161, A1706-A1715.

33. R. Black, S. H. Oh, J. H. Lee, T. Yim, B. Adams and L. F. Nazar, J. Am. Chem. Soc., 2012, 134, 2902-2905. 